\title{
8 How Standard Zhuang has Met with Market Forces
}

\author{
Alexandra Grey
}

\section{Introduction: Standardizing Zhuang and Mandarin in the 20th Century}

Zhuang is the contemporary name (in Mandarin and English) of both a language and a people recognized as the largest of the 55 official minorities of the People's Republic of China (China), by population (Guo et al., 2015: xv). Zhuang language originated in what is now South-Central China, where the Tai languages - to which it is related - developed about 2500 years ago (Luo, 2008a: 9). Zhuang developed into many dialects, which linguists as well as speakers now group into Northern Zhuang and Southern Zhuang (Holm, 2013: 27; Li \& Huang, 2004: 239; Lu \& Li, 2012: 19). Zhuang was standardized in the mid-20th century, in parallel with the standardization of other minority languages that had recently been officially recognized in China, and also in parallel with the standardization of the highly-varied majority language, Mandarin, to create one national Mandarin variety called Putonghua. Other chapters in this book note some of these parallel standardization processes for other officially recognized minority languages in China (see $\mathrm{Wu}$, this volume, on Mongolian and Rigdrol Jikar, this volume, on Tibetan) and also for Mandarin (see Feng, this volume). The following section of this chapter explains the mid-to-late 20th-century standardization of Zhuang as a process creating an icon rather than a lingua franca, making it dissimilar to the contemporaneous creation of lingua franca Putonghua through the standardization of Mandarin.

The mid-20th-century context of establishing a new and communist Chinese nation, a context in which language standardization was a state priority, changed radically once China began marketizing in the late 1970s and quested after global economic strength. The question for the remainder of this chapter, then, is how markets have valued this emblematic but not widely-used Standard Zhuang. In addressing this question, the 
chapter will focus on whether Standard Zhuang has become a skill desired by employers (which I link to Standard Zhuang's place in education) or a marketing resource, i.e. whether Standard Zhuang is a commodified identity resource. An economic value for a language practice may be constructed by markets in other ways, e.g. through a national curriculum, or as a profitable performative resource in tourism, but there is space here only for a few pertinent comments about my findings relating to how Zhuang has been constructed in education and tourism. The chapter will focus rather on empirical data about Standard Zhuang as a job-seeking resource, and about Standard Zhuang as a way of communicating commercially through advertising and product packaging, to illustrate how the lack of market value for Standard Zhuang is aggravating Standard Zhuang's obsolescence. These empirical 'snap shots' are drawn from my 2013-2017 research into Zhuang language policy in practice, which also analyzes many sociolinguistic changes that Zhuang is encountering and the role of language policy in propelling or responding to these changes (Grey, 2017, 2021b). I conducted multisited ethnographic fieldwork in four cities in China, anchored on universities at which Zhuang language was taught. This included interviews with 23 university student participants from Zhuang-speaking backgrounds and 20 with experts/community leaders, as well as linguistic landscape studies (see further Grey, 2017: 103-160; Grey, 2021b, which extends the data beyond 2017). The data were analyzed using legal and Bourdieauisan critical sociolinguistic approaches. This chapter uses my study to build upon older literature in order to narrate how standardization and marketization have interacted. I reflect, in conclusion, on this as a cautionary tale of the limits of standardization to future-proof a minoritized language.

This chapter is - deliberately - not freighted with deep theoretic discussion, but it draws upon Bourdieusian critical sociolinguistic conceptualizations of 'symbolic power' (Bourdieu, 1977, 1991) derived from the exchange of linguistic, economic, cultural and social 'capital'. From this perspective, some language practices are treated by members of society as having not only linguistic utility but also non-linguistic capital, for example, cultural prestige or strong money-making potential, and therefore such language practices come to be a source of symbolical power for those who use or control them. Conversely, language practices that do not appear to make money, or which are treated as culturally impoverished, may be taken as signs of the users' lack of economic, cultural or social capital, rather than empowering their users. Because of the exchange between various capitals, Bourdieu theorizes, these devalued languages may even be believed to be deficient for linguistic purposes - i.e. having low linguistic capital - despite many linguists believing that all language varieties are inherently capable of expressing ideas and enabling socially-useful communication. A critical sociolinguistic conceptualization of language as a resource has developed as an 
extension of Bourdieu's analysis of this economics of linguistic exchange, spurred by Heller (e.g. 2010). Language resources - whether resources for communication, identity-building, economic mobility, etc. - are in unequal distribution, because linguistic capital, cultural capital and other forms of capital are unequally distributed. This is an important idea for understanding how social inequalities and language variation can intersect. With this theoretical outlook, I treat language policies, including standardization policies examined in this chapter, as structures mediating and regulating the availability and value of language resources, capital and symbolic power.

Bourdieusian sociolinguistic theory goes hand-in-glove with the theoretical concept of 'language ideologies'. The beliefs that shape the enduring association of certain language features or practices with particular social categories, places and values are known as language ideologies in the literature (see further Piller, 2015: 920; Woolard \& Schieffelin, 1994: 72), while such associations are known as the 'indexical meanings' of language. Language ideologies, together with socially-situated practices, are objects of inquiry in this study and in critical sociolinguistics generally because they facilitate the investigation of the social reasons for patterns in the use and disuse of languages and also the investigation of disjunctions between 'overt' and 'covert' language policies (Shohamy, 2006: 51-52). In Bourdieusian critical sociolinguistic theory, language ideologies provide a hierarchal structure to each person's socialized disposition (known as 'habitus'), through which they understand and judge their own and others' language practices and those practices' links to social identities. These ideologies may be instantiated on a societal level as norms, and produced, challenged or reproduced in discourses, especially discourses with symbolic power such as laws about language recognition and a government's standardization rules or policies.

Such laws, rules and policies about languages make some language varieties 'hard edged', imbuing them with 'considerable symbolic power as part of the dominant discourse' (Freeland \& Patrick, 2004: 8, following Bourdieu, 1991), but they also exclude or delegitimize certain language practices and certain constructions of languages, their indexical meanings and their values. Elsewhere in this volume, Ying Sargin offers a clear illustration of this: the Sibe language variety has been lumped with the arguably distinct yet officially recognized Manchu minority language in China, thus never gaining its own hard edges or symbolic empowerment through formal recognition. Beyond China's borders, Saltzmann's chapter similarly examines the language ideologies and language policies which deny Jejueo hard edges in South Korea and the vulnerability this creates for a now-endangered language; indeed, it is the existing language ideologies and policies that endanger Jejueo. Standardization policies did, however, give Zhuang language and the official Zhuang minority polity some hard edges in China, as I will now explain. 


\section{Standardization Policies and Practices}

\section{Characteristics of Standard Zhuang}

Importantly for standardization, the region of South China in which Zhuang originated and became widely spoken remained on the periphery of the Chinese imperial state, and neither the languages nor the societies of the Southwest's 'tribal people' (Tapp \& Cohn, 2003) were fully integrated into the imperial state. One consequence of this was that Zhuang language was never standardized by imperial processes. However, in the lead up to, and immediate aftermath of, the establishment of the People's Republic of China (China) in 1949, it became socially and politically significant to officially recognize a Zhuang ethno-linguistic group. The group's delimitation was made largely on the basis of shared language practices, as attested to by the classification team leader Fei Xiaotong (Brandist, 2005: 64; Kaup, 2000: 127; Mullaney, 2006: 8, 55). Zhuang had never previously been standardized by the state (Holm, 2008: 416). Now, the state initiated and funded the standardization of dozens of newlyrecognized minority languages.

Significant changes were introduced to Zhuang through this standardization. (Organic, contact-induced changes have since developed, too: see Lu \& Li, 2012.) Language policies about Zhuang fell into two phases: the early 1950s' initial standardization and the 1980s' reforms. A step preliminary to the initial standardization was to categorize all newly-recognized minority languages according to whether they were previously written. For those such as Zhuang that were officially deemed to have never had a written script, standardization then focused on developing a script in addition to a pronunciation standard, an orthographic standard and a grammar $(\mathrm{Li}$ \& Huang, 2004: 240-243). The newly developed writing system was called Zhuàngwén ('Zhuang writing': Holm, 2008: 415), and its script used the Roman alphabet, as did all the scripts for the minority languages categorized as having not previously been written. The 1950s' Zhuangwen used Latin, Cyrillic and International Phonetic Alphabet (IPA) letters, because it was developed by Russian scholars working with Chinese linguists (Luo, 2008b: 321; see further Ager, 2016; GZAR Minority Language Working Group Research Team, 1984; Li \& Huang, 2004; Sinj \& Loz, 2008; Wang, 1979, 1983). This alphabetic or 'Romanized' script was developed with an overarching goal of minority language standardization in mind: enabling mass literacy (Premaratne, 2015; Rohsenow, 2004; Zhou, 2001, 2003). The literacy planners' objective was therefore a writing system that would be transparent to Zhuang speakers and thus 'easy to learn' (Li \& Huang, 2004: 244). However, script development and the teaching of Standard Zhuang ceased during the Cultural Revolution (Luo, 2008b: 321), so the 1950s' Standard Zhuang was not widely learnt.

Standard Zhuang became a topic of active language policy again after the Cultural Revolution in the 1980s, when Zhuangwen was reformed to 
make it easier to print (Zhou, 2003: 251-258). Cyrillic and IPA letters were removed from the script, leaving only Latin letters. The contrast between early and later Zhuangwen can be seen in this example of the Standard Zhuang word for 'Zhuang language': Vabcueyb (pre-1982) and Vahcuengh (current); cuengh is 'Zhuang'. These words show a feature of Standard Zhuang orthography as well: the use of letters as tone markers. In Vahcuengh, the $h$ at the end of each syllable represents the sixth tone. In contrast, the Romanized, auxiliary writing system for Putonghua, the national standard language, uses diacritics for tones and this makes Romanized Putonghua visually distinct from Zhuangwen, at least when the diacritics are included: e.g. 'Zhuang language' is zhuangy̌ in Putonghua. The primary official script of Putonghua is simplified characters, which is even more visually distinct from Zhuangwen.

There was also a reform of the orthography of Standard Zhuang in the second phase of standardization. Initially (from 1957), tones were represented by non-Latin letters which resembled the form of the Digits 2-6 (the first tone was unmarked): -Z (2nd); -3 (3rd); - Ч (4th); -5 (5th); - - (6th). Since 1982, these have been replaced by -Z, -J, -X, -Q, - H (and their lower case forms). Also since 1982, variants of the third and sixth tones are represented too, by $-\mathrm{p} / \mathrm{t} / \mathrm{k}$ and $-\mathrm{b} / \mathrm{g} / \mathrm{d}$, respectively. The 1982 reforms mean that Standard Zhuang is now written using all of the 25 letters which are used to write Putonghua in its Romanized auxiliary script (which does not use $v$ ) and all 26 letters of the English alphabet, and no others. Thus, achieving the economy of scale of being able to print and type Zhuang using standard technologies has meant removing its distinguishing graphemes.

The standardization of Zhuang centred on the development of a new writing system because, as noted above, Zhuang was treated as having lacked one. In fact, Zhuang had been written down historically by Zhuang speakers for at least a thousand years (Holm, 2008: 415; Luo, 2008b: 320), using systematized but not standardized sets of graphemes including rebus forms of Chinese characters and indigenous characters (see Holm, 2008: $415,2013)$. The low prestige of this older writing system is indicated by its exclusion from the official standardization of Zhuang; in Bourdieusian terms, we could say that historic ways of writing Zhuang were not invested with symbolic power by the state. The low prestige is also conveyed in one of Zhuang writing's common traditional names, Sawndip, which literally means 'uncooked characters' (Sawndip is a loan word in English and is Sawndenj in Zhuangwen). These graphemes were 'uncooked' in the metaphoric sense of being unprocessed by the application of imperial language standards, and 'uncooked' implied that the writing and its users were 'uncivilised', as Holm notes (2008: 415). Yet Holm (2008: 415) reports that 'many literate people in Zhuang society' still used this older writing system; it had not necessarily been seen as lacking cultural or linguistic capital by Zhuang peoples. But Zhuang had lower status than Mandarin, 
the language associated with the prestigious, imperial civilization and Chinese majority culture and, historically, Zhuang was associated with an area seen as poor and culturally peripheral. Thus, Zhuang has had little cultural, political or economic capital to exchange; that even the linguistic capital of its traditional writing system was then undervalued and not recognized by the state is a clear example of the exchange of capital that Bourdieusian theory predicts and uses to explain how language varieties take on social meanings. Thus, from the start of the standardization of Zhuang, there was a lack of symbolic power with which to imbue the preexisting Zhuang writing system, nor was that writing system believed to be civilized and sophisticated enough to raise the value of Zhuang language in the dominant discourses of those with power. The provision by the state of standardization was, rather, an effort to 'capitalize' Zhuang, to increase its status by providing it with the cultural, political, educational and economic capital thought to inhere in standardized languages. Similarly, the concomitant regulation of a new character for 'Zhuang' in Putonghua (壯, then simplified to 壮) to replace two derogatory characters which had been used for 'Zhuang' was an effort to revalue Zhuang and change widespread beliefs about it that derogatory characters reproduced.

Zhuangwen writing was developed in tandem with standards for grammar and pronunciation (see Guangxi Language Reform Committee, 1989), based on the Northern Zhuang dialect of Wuming (Luo, 2008b: 321; Ramsey, 1987: 236). Li and Huang (2004: 241) suggest that Wuming Zhuang was chosen as a model for Standard Zhuang because of Wuming's proximity to Nanning, the capital city of the Guangxi Zhuangzu Autonomous Region (GZAR), the region considered to be the Zhuang language heartland; that is, Wuming Zhuang was seen to have relatively high culturally, political and/or economic capital. Others suggest it was because the pronunciation of this areal dialect 'was considered to be Northern Zhuang but with characteristics of Southern Zhuang' ('Standard Zhuang', 2018), i.e. accessible across the Zhuang varieties. In any case, Standard Zhuang was new to everyone; it was therefore not something any Zhuang speakers would happen to learn in childhood (or adulthood) or that would become a lingua franca without exposure and teaching. The next section explains, however, that exposure and teaching were not forthcoming.

\section{Standard Zhuang as a lingua franca}

To become a lingua franca, a standardized variety needs to be widely known and used. Standardizing Zhuang and other minority languages was a prioritized goal before the Cultural Revolution, but enabling people to use Standard Zhuang was less of a priority, and did not become one after the Cultural Revolution either. Although adult classes in reading and writing Zhuang were initially offered by the state, neither specific training 
in Standard Zhuang nor more general bilingual Zhuang education were widely available during the Cultural Revolution, 1980s or 1990s (Zhou, 2001: 56). My study confirmed that this remains the case today; thus, learning Standard Zhuang has been restricted. I used the most recent data available (from 2004-2005) to calculate the proportion of school-aged children from the Zhuang minority group who were enrolled at bilingual Zhuang-Putonghua schools in GZAR in the early 2000s: The proportion was not quite $1 \%$ (Grey, 2017: 90). Because these bilingual schools are one of the few ways to access formal training in Standard Zhuang, the very low figure indicates that most Zhuang children nowadays are not becoming speakers, readers or writers of Standard Zhuang. Even 'bilingual' schools do not necessarily teach written Standard Zhuang at all, or use spoken Zhuang beyond the first few grades. Moreover, community leader participants reported to me that the number of Zhuang bilingual schools has reduced further since the early 2000s.

The other way to access formal training in Standard Zhuang is through a small number of university degree programs, particularly the SouthWestern Minority Language and Literature programs (I will call these 'Zhuang Studies') offered at four universities, which together admit roughly 100 new students each year (Grey, 2017: 404). Although written Standard Zhuang is taught from a beginner level in that degree, most classes are not Zhuang-medium, and students do not use spoken Standard Zhuang as a lingua franca; they usually use the national lingua franca, Putonghua. For example, 'Yvonne', a Zhuang Studies student, described to me the lack of a common variety of Zhuang amongst her classmates in 2014:

壮语, 它的方言差别经常是比较大, 大到听不懂的程度......因为我们现在
在学习这个专业, 所以我们在专业里我们会有比较多的壮语同学。呢, 因
为搞通了手们平时主要是用普通话, 但是有情况用壮语开玩笑……你一
定要说然后说慢一点儿。
(Zhuang languag, its dialectal differences are often relatively big, big to
the degree of hearing but not understanding ... Because we are now
studying this major [Zhuang Studies], so in this major we have quite a lot
of Zhuang language[-speaking] classmates. Hmm, because we can't com-
municate we usually must use Putonghua, but there are situations in
which you can joke in Zhuang ... [For that] you need to speak slower. My
translation.)

Moreover, the majority of my study's student participants who spoke about written Zhuang believed and/or had personally found that a Zhuang speaker cannot learn to read or write Zhuangwen without specifically being taught to. Their difficulties contrast with the easy, transparent orthography and script that the Zhuang standardizers aimed for. Thus, Standard Zhuang is a resource or skillset to which access is restricted. Standard Mandarin, i.e. Putonghua, however, has been made widely accessible. 


\section{Putonghua as an alternative lingua franca}

At the same time as China recognized and standardized minority languages, it recognized one ethno-linguistic group, the Hanzu, as the majority. The language associated with this group is Hanyu, known as Mandarin or Chinese in English. Mandarin, like Zhuang, is actually a grouping of many language varieties, and standardizing the varieties of the majority language was also a 1950s priority policy. This built on an established practice of the state standardizing Mandarin script dating back two millennia (Holm, 2008: 416). However, unlike the standardization of Zhuang, the standardization of Mandarin produced a spoken and written variety that was to be propagated nationwide: Putonghua ('the common language').

This standardization of Mandarin initially included a policy to replace the Chinese character script with an alphabet to make literacy in the common language easy to acquire. That controversial idea was soon abandoned (Premaratne, 2015: 426, 433; Rohsenow, 2004: 22-23). Mandarin standardization policy quickly refocused on the simplification of the stroke-heavy traditional characters, still with a view to making literacy more accessible. Mass literacy and a national lingua franca were seen as essential to economic development. In contrast to the non-promulgation of Standard Zhuang, the state invested, and continues to invest, significant resources in the promulgation of written and spoken Putonghua, particularly through compulsory schooling. In recent decades, it has also invested heavily in teaching English in schools and universities nationwide.

The promulgation of Standard Zhuang is now a low government priority, but by contrast, making sure Putonghua is taught and learnt well across China, and increasingly overseas too, has risen as a policy priority. So, although Zhuang still has many speakers, the majority of them also speak Putonghua and many write it, while some Zhuang group members no longer speak Zhuang at all. Some 10 million people within China are reported as Zhuang speakers in recent literature (Ager, 2016), including about two-thirds of the Zhuang minority group, as well as the smaller numbers of Zhuang speakers who are from other official ethnic groups. These are speakers who have 'naturally' acquired a Zhuang dialect, not necessarily - and not likely - the 'inorganic' Standard Zhuang.

Some $84.95 \%$ of people who speak a Zhuang variety as a mother tongue reputedly used it in their everyday lives at the beginning of this century (Chen \& Wang, 2005: 52), but the linguistic repertoires of today's Zhuang speakers are different to those of mid-20th century Zhuang speakers, many of whom did not speak Mandarin or any language other than Zhuang. Li and Huang (2004: 240) report that $42.29 \%$ of the official Zhuang group population were still monolingual in Zhuang in the 1980s, 
but Zhou (2000: 142) reports that by 1990, 57\% of the Zhuang were 'Chinese' (i.e. Mandarin) speakers and that the majority $(66.15 \%-77.99 \%)$ of the Zhuang group were Zhuang-Mandarin bilinguals by the early 2000s (Zhou, 2012: 6,10). Nevertheless, while Zhuang speaker numbers are relatively high, not only is the literacy rate low for the Zhuang group relative to the national average, but furthermore most of the Zhuang people who are literate are literate in Putonghua (Zhou, 2001: 56, and in communications with the author, 13.12.2017, at the conference at which this chapter was first presented).

\section{Standard Zhuang as an icon}

There can be policy goals behind language standardization other than creating a lingua franca, and one is to create a stable object that can be celebrated as a symbol of a speaker group/culture/nation. The linguistic anthropologists Irvine and Gal (2000) call this process 'iconising' a language, emphasizing that this is a process through which beliefs (or language ideologies) come to be shared about which features of a language count as valorized, about emblematic forms and about whom the icon represents. While Standard Zhuang was not used as a lingua franca, it was quickly deployed as an icon of the Zhuang group by the government, and assemblages of minority groups' icons were (and are) often used by the government to represent China's diversity to its own citizens. Indeed, providing each minority group with a standard language demonstrated formal equality and reinforced the state's new grouping of people who spoke Zhuang as a discrete polity; a state-standardized language is a tool for increasing the symbolic power and hard edges of a people or polity with whom that language is officially associated. Because the government has used Standard Zhuang more in written form than the spoken form (e.g. disseminating policies and information, archiving literature), and because writing can be displayed in permanent and publicly visible ways, written Standard Zhuang has been iconized more than oral Standard Zhuang.

The prominence of Standard Zhuang in the painting shown in Figure 8.1 illustrates how symbolically important the standardization of Zhuang was in the 1950s, as part of creating a new Chinese nation of and for its diverse peoples. The painting depicts minority ethnic peoples in a celebratory march and is now displayed inside the Anthropology Museum of Guangxi (a museum about minority groups) and captures languages in the process of being standardized. The first line on the marchers' banner is Zhuang in then-new Zhuangwen, still including Cyrillic letters. The second line is Mandarin: most of these characters happen to be the same in traditional and simplified form, but 区 is simplified, and the line refers to the establishment of the 广西僮族自治区 ('Guangxi Zhuangzu 
Autonomous Region'), which happened in 1958. However, 'Zhuang' here is written with the old, pejorative character 僮, which also means 'boy servant', although within the distinctly modern compound word Zhuangzu. The new standards for simplified Putonghua writing were still developing, and the new, non-pejorative character for Zhuang (壮) was not made official until 1965.

Standard Zhuang is presented in this example as closely associated with the Zhuang group and territory and was initially used to galvanize the identity of this new group, in parallel with the processes of standardizing Mandarin and then using the standard to represent and galvinize a Chinese national identity. That the government took care not to use other varieties of Zhuang enhanced the iconic status of Standard Zhuang. However, there is little evidence that authors other than the government used or use written Standard Zhuang to symbolically represent the Zhuang people, nor even for the purpose of writing Zhuang down (Grey, 2017: 231-311, 2021b). Some continued to use Sawndip to write Zhuang, but this skill has not been not widely acquired given its historically limited social access and the lack of government backing for teaching it. Sawndip is rarely used as a visual icon representing the Zhuang language, Zhuang speakers or Zhuang people.

Once an icon exists, it can be commodified, because it is an objectified form of language. It is to the processes of commodification, and other uses and valuations of Standard Zhuang in marketized China, that we now turn.

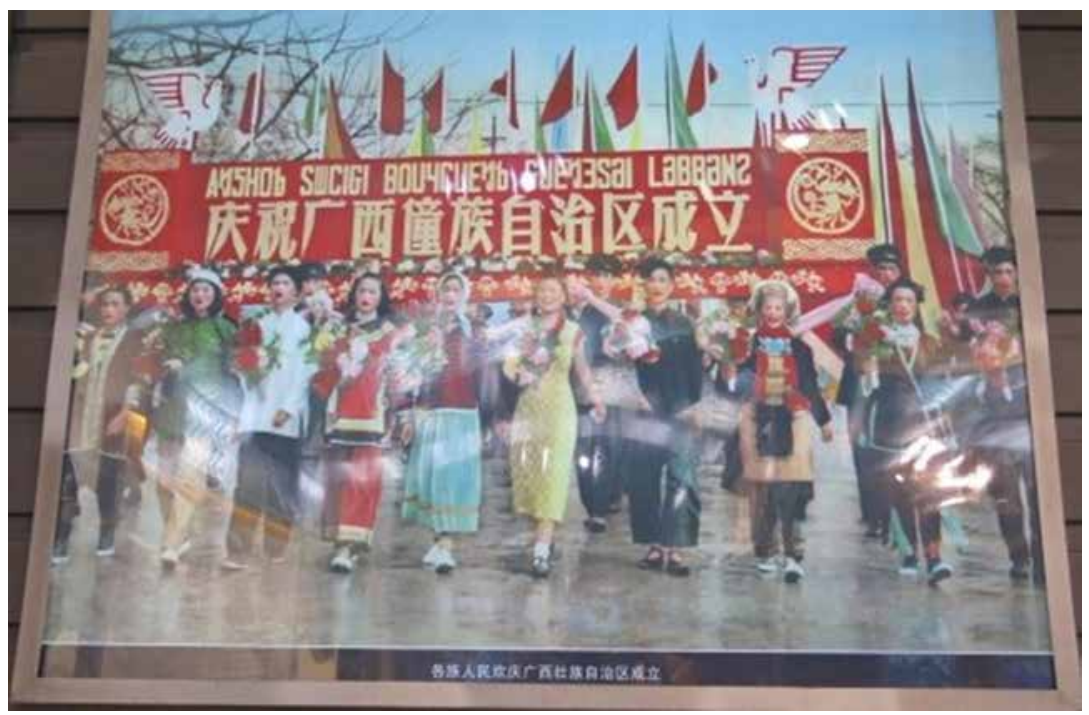

Figure 8.1 Artwork in Guangxi Museum for Nationalities (author's photo, 2014) 


\section{The Market for Lingua Francas and Icons}

China was well known during the initial minority language standardization era for its centrally planned economy. However, in the late 1970s, significant policy reforms opened China to market forces. This allowed for international trade, but it also meant that employment and education within China became marketized. Individuals started to compete sometimes provincially and sometimes nationally - for places in schools and companies, while some schools and many employers came to rely on profits rather than state funding to operate. In particular, central government funding for bilingual Zhuang schools reduced and the funding burden shifted to typically poorer county governments (Grey, 2019a: 462-463). Initially, the traditionally Zhuang-speaking areas of South China did not attract investment or grow economically at the rapid pace of China's East Coast, but a sustained investment push from the central government this century has catalyzed local economic development in these areas, and migration to cities is one consequence.

The dispersal of groups sharing a Zhuang areal dialect has not caused uptake of Standard Zhuang; as noted in the last section, Putonghua has become entrenched as the lingua franca instead. There are also regional Mandarin dialects which act as regional lingua francas within South China. Instead of widespread use of Standard Zhuang as a lingua franca in GZAR, Putonghua is the lingua franca in government communications and commercial communications. My participants reported that in informal speech, non-standard, regional Mandarin varieties are also used as local lingua francas e.g. Nanning's Baibua ('Vernacular'). This non-usage of Standard Zhuang is reflected in and reinforced by the lack of value given to Standard Zhuang as an employable skill, which is part of the common belief in Zhuang's lack of economic capital.

My study investigated beliefs about employability in relation to Zhuang language and types of work in which Standard Zhuang is used. The scarcity of people who know Standard Zhuang could, after all, make that knowledge valuable. I found evidence that in a niche market of government-created jobs in Zhuang language translation, media, teaching and research, this is the case. For instance, a small number of ZhuangPutonghua translators are employed in government translation bureaux in Yunnan Province and GZAR. However, a participant who had worked in one of the bureaux reported to me that when translators retire they are no longer replaced (Grey, 2017: 414); the scarcity of professional-level Zhuang translation skills is no longer creating value there. Another small cohort are employed to make Zhuang-medium media for state media corporations, namely for the televised Zhuang Language News, a now-bilingual program that actually relies on Putonghua (Grey, 2017: 266-267) and a Standard Zhuang-medium newspaper which I found was published irregularly in GZAR. Some Zhuang Studies graduates who have learnt 
Standard Zhuang can still obtain employment as researchers on university projects looking at Zhuang language, or as teachers at the relatively small number of bilingual schools, but the state no longer guarantees Zhuang teaching jobs to graduates, because employment in the sector is now marketized, not centrally planned, and because the lack of a market is causing a reduction in the number of bilingual schools. I interviewed an academic who teaches Zhuang as part of a Zhuang Studies program. He had insight into the job prospects that arise from learning Standard Zhuang:

\begin{abstract}
这种岗位是有限的, 这种民族语的岗位, 它很快就会饱和了……就是说学 生培养了几年之后, 他招够了.......就是会面临一个……连续招人的这么一个 问题。所以这个现在还是很着急的。

(That kind of post is limited, that kind of minzu[minority group] language post, it will soon reach saturation point ... That is to say, the students are nurtured for a few years then a sufficient amount are attracted [for the available postings] ... So, then they [authorities] could face ... a continuous recruitment problem of sorts. So now this is very worrying. My translation.)
\end{abstract}

This was especially worrying for this teacher and his students because they were part of a new Zhuang Studies program which had then, in 2014, not even produced its first crop of graduates, yet oversupply was already imminent. This is not unexpected: The first cohort of eight graduates from a specialist Naxi-language degree at the same university obtained most of the available specialist jobs while the later graduates struggled to find work (Yang, 2012: 69-71). Outside this narrowing niche of government-funded language work, jobs requiring or valuing Standard Zhuang are rare.

It is not only a preference for languages which index bigger markets (e.g. Putonghua and English) and thus have symbolic power deriving from their economic and mobility capital, nor a lack of Zhuang-medium education opportunities which have caused Standard Zhuang not to be a highly employable skill. Rather, the Law of the People's Republic of China on the Standard Spoken and Written Chinese Language, introduced in 2000, also 'encourages' and in some sectors even requires Putonghua as the medium of communication in many commercial activities, e.g.:

- Art.13: 'The standardised Chinese characters shall be used as the basic characters in the service trade ... People working in the service trade are encouraged to use Putonghua when providing services'.

- Art.14: 'The started spoken and written Chinese language shall be used as the basic spoken and written language in ... facilities in public places; ... signboards and advertisements; ... names of enterprises ... ; and packaging and specifications of commodities marketed in the country'.

- Art.19: Workers in roles which 'require' Putonghua must have a 'Putonghua ability' meeting certain standards, with higher standards 
set for publicized work (e.g. broadcasting and actors) and public sector work (e.g. teachers and state functionaries). (See Luo, this volume, for the Putonghua test used to assess this standard.)

This legislation does not prevent the auxiliary use of Standard Zhuang, but it does ensure that Zhuang cannot be the primary medium for these types of work. Moreover, as Standard Zhuang is understandable to so few, it does not help reach many customers or clients; thus, the market does not value a product more highly for having additional Zhuangmedium packaging, or value a service more highly for having been offered bilingually.

This pro-Putonghua language policy is not coincidental with marketization. Rather, pushing for a national lingua franca has been part of fusing local markets and infrastructure into an efficient national market, and part of a nationwide push to increase levels of education so as to increase people's contributions to the economy. But this also means that knowing Putonghua is no longer a specialist skill; it has become integral to the mandatory, publicly-funded years of schooling and a formalized threshold requirement for most university degrees, as well as for many jobs. That university entrance exams are conducted almost exclusively in Putonghua is a critical factor in the market devaluation of Zhuang and the unwillingness of children and parents to invest time in learning Zhuang in schools. Six minority languages, including Zhuang, are permitted by law to be the medium of these exams. However, given there has long been almost no Zhuang-medium secondary school education, and little emphasis on written Zhuang in the limited bilingual primary schooling available (Grey, 2017: 358-441), parents and schools have little desire to push for this permission to be realized.

It is under these conditions that people have started to develop a belief about language which I call a 'zero-sum language ideology' (Grey, 2017: 389, 2019a: 475): Some families, schools and officials think that the time and effort needed for a child to learn any Zhuang will not only not improve their education and job prospects, but furthermore it will detract from the time and effort the child can put into learning Putonghua and English, which are seen as valuable for employability. Thus, as one bilingual education expert I interviewed expressed:

\begin{abstract}
他们认为我的小孩来学汉语都已经够辛苦的了, 还要学英语, 然后我还学 壮语, 我这个小孩哪有那么多时间来学习, 反对学这个壮语。

(They [parents] think 'our children are already toiling away at Mandarin, then they must study English, then Zhuang on top, my child only has so much time', they oppose studying this Zhuang. My translation.)
\end{abstract}

On this logic, learning Standard Zhuang is even more costly than learning the parents' own Zhuang dialect because learning Standard Zhuang requires additional resources. Moreover, it is widely considered valuable not 
only to learn Putonghua but to pronounce it in the standard way, and many people believe that children who speak Zhuang (whether Standard or nonstandard) will never be able to pronounce Putonghua, they will speak socalled 'Jia Zhuang' ('Pinched Zhuang' i.e. to speak Mandarin with 'pinches' of Zhuang). As one student (coded 'Tansy') puts it:

城市的孩子是不会讲壮语的。因为他们父母的话怕, 就是会影响到普通话 的发音, 所以就不让讲壮语。但是他们听得懂。

(City kids cannot speak Zhuang language. Because their parents fear this [Zhuang] can influence Putonghua pronunciation, therefore they don't let them speak Zhuang language. My translation.)

The social recognition of Pinched Zhuang as a language variety is a classic example of language practices being socially ascribed low cultural and educational capital, which undermines even the linguistic value of a language variety; Pinched Zhuang is a language variety that indexes an undesirable social status, as the pejorative meaning of its name reflects.

The use of examination in English as an additional gatekeeping tool as students matriculate through school, and sometimes as a job requirement (responding to linguistic norms of the global market), exacerbates this pressure not to invest personal, familiar or scholastic resources in Zhuang. My interview and observational data suggest a lack of market demand for schooling in Standard Zhuang: parents and communities are not pushing their county decision-makers to fund Zhuang-medium education; employers are not asking the Department of Education to develop a workforce trained in Standard Zhuang.

Moreover, the pro-Putonghua legislation reproduces the normative centrality of Putonghua in commerce. My study investigated whether this was discursively reproduced in the built environment, the so-called 'linguistic landscape', and found that it was. As China has marketized (and urbanized), advertising and commercial discourses (both national and international, and both written and spoken) have become part of the everyday linguistic landscapes; I found that they are predominantly in Putonghua, with some English. I found that Written Standard Zhuang is treated as being of little commercial value either in informational or symbolic functions, to apply Landry and Bourhis' (1997: 23) canonical division of signage functions. It appears that Zhuang does not index commerciality itself, nor does it index the kinds of qualities and places which advertizers discursively associate with products to make them sell better. These results are discussed in depth in Grey (2017, 2021b). Further, I found that non-commercial public texts are also predominantly in Putonghua, even in GZAR, although certain government-authored genres of signage in GZAR do include Zhuang (namely, bilingual street-name signage in GZAR's capital city, Nanning). When Zhuang is included on noncommercial signage, I found it is always Romanized, i.e. Zhuangwen, consistent with the official script standardization, which is reiterated in local 
regulations that standardize the format of such signage. The semantic signal of the standardized format of these Zhuang-inclusive texts is that Zhuang is marginal, less important for transmitting information than Putonghua (see e.g. Figure 8.2). Moreover, when Nanning's bilingual street-name signage is viewed alongside nearby texts and other semiotic displays, the Zhuang streetname seems but a whisper in a chorus of Putonghua. I argue in my book (Grey, 2021b) that this government-authored use of Standard Zhuang is a kind of city branding that uses Zhuangwen as an icon of local heritage, and there, as well as in my study of Zhuang in tourism (Grey, 2019b), I have argued that Zhuang is an anti-commercial symbol.

To highlight just one concrete example, the background of Figure 8.2 illustrates the near-invisibility of Standard Zhuang in everyday urban environments which I regularly found in my fieldwork. This photograph foregrounds one of the few genres of language display to include Zhuang, bilingual street-name signs in Nanning City and in the satellite towns under the Nanning Municipal Government. However, the photograph shows that street-name sign surrounded by Putonghua-dominated commercial texts on this downtown street of one of the municipal satellite towns, Wuming, as was typical. Consistent with the findings reported above, these street-name signs and the few other public displays of Zhuang that I found were government-authored.

On these bilingual street-name signs, the toponym is provided in Standard Zhuang (top line, in Zhuangwen) and in Putonghua (second and third lines, in characters and Romanized script). An additional component of text, presented only in Putonghua in a lower white section, gives the cardinal directions and sometimes this section also includes the names of adjacent streets (as in Figure 8.2). These Putonghua-Zhuangwen streetname signs have appeared on most streets of Nanning (including in this

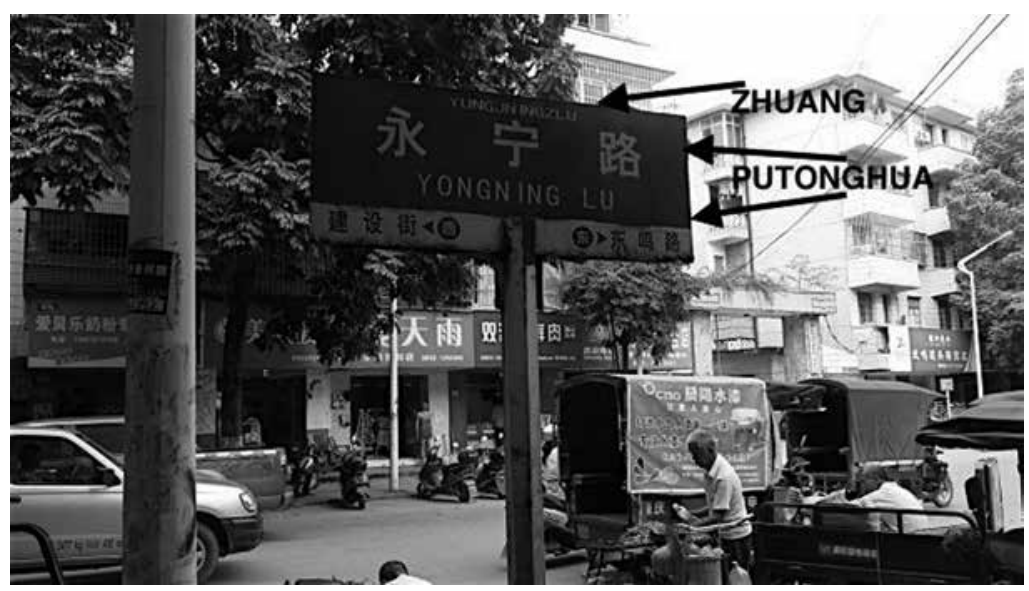

Figure 8.2 Streetscape, downtown Wuming (author's photo, 2015) 
urban satellite, Wuming) in the past decade, although occasionally I found older, monolingual Putonghua street-name signs there. Moreover, I found that the Zhuangwen toponyms on these street-name signs were not included in local maps or digital maps: The Putonghua names are the official and circulating street names.

Furthermore, it may be that the commodification of the written form Standard Zhuang, in particular, has been stymied because reforms made it look like English and Putonghua Pinyin, as I observed above. There is little research on this, but my study found that the standardization of Zhuangwen has made written Zhuang vulnerable to being misrecognized as English, because they share an alphabet and because people are habituated to seeing English in public (Grey, 2017, 2021b). Two Zhuang-speaking students, 'Laurel' and 'Zeina', discussed this with me in 2014:

Laurel: 因为它这个是拼音文字, 没什么人看, 看不懂。略过去也觉得 它是英文或者是拼音这种, 但是又不是拼音, 所以他不会觉 得这个是壮文。

Researcher：对啊。

Zeina: 看起来像英文一样, 我觉得。

(Laurel: Because it [signage] is pinyin script, no one pays it any regard, they can't read it. In the recent past, people even thought it was English or [Putonghua] pinyin, something of that nature, but it is not [Putonghua] pinyin, so they could not conceive of it being Zhuang script.

Researcher: Right.

Zeina: $\quad$ To look at, it looks the same as English, I think. My emphasis, my translation.)

Moreover, some participants reported mistaking Zhuangwen for Romanized Putonghua, as did the residents in Nanning, as reported in newspapers, who complained about signage in what they believed to be incorrect Romanized Putonghua ('南宁路牌 [Nanning Street Signs]', 2009). In addition to low literacy in Zhuang, another reason why people are habituated not to recognize written Standard Zhuang, even if they are Zhuang speakers, is that publicly displayed text is mainly in Putonghua, as I emphasized above in summarizing my linguistic landscape studies.

This snapshot illustrates how Standard Zhuang is not used for conveying information in commercially-oriented public texts, or many other public texts, even in GZAR. I argue that this is at least in part because the standard has not been promulgated as a lingua franca but also because the language icon produced by standardization has not been commodified (elsewhere, I develop the related argument about this icon not being recognizable: Grey 2021a). The symbolic or cultural capital of written Zhuang does not exchange into economic value; customers and clients do not pay to see 'their' language represented in commercial texts, and others do not pay for any exotic or local affinities created by associating Zhuang language with a product or shop. 


\section{Concluding Reflection}

This chapter explained how the standardization of Zhuang, which took place largely before China marketized, created a linguistic icon but not a lingua franca. It has argued that once Standard Zhuang was developed, it did not take off because it was not designed or taught in ways that made it easily understood by Zhuang speakers or a useful lingua franca. These problems have been exacerbated since employment in China ceased to be centrally planned and instead became a competitive market. Other than within a nearly-saturated minority language work niche made viable by government funding, commercially-oriented employers do not seek people to communicate with co-workers or customers in Standard Zhuang. Schools do not produce many people proficient in Standard Zhuang either; I argue that the lack of employability of Standard Zhuang derives from but also maintains this lack of demand for Zhuang-medium education; Standard Zhuang is widely believed to have very little economic or educational value, feeding back into even a linguistic devaluation of Zhuang varieties.

Moreover, because written Standard Zhuang is not easily recognized as Zhuang without access to education in Zhuang literacy, its iconicity seems largely limited to 'in-the-know' state authors: non-state discourses do not iconize written Standard Zhuang. Because of (at least in part) the lack of widespread representations by diverse authors of written Standard Zhuang language as an icon of the Zhuang, and because of its low recognizability, this icon has not been commodified. But nor has traditional Sawndip been commodified. There are likely multiple reasons why Zhuang speakers did not transform Sawndip into a linguistic icon; important among these must be that the government's consistent treatment of Romanized Zhuang as the first and only way to write Zhuang made it hard to learn, use, represent or iconize Sawndip; Sawndip has none of the symbolic power with which state recognition and resourcing can invest a writing system. Moreover, without Sawndip literacy, Sawndip characters are hard to distinguish from Mandarin characters. However, learning Sawndip these days is a symbolic expression of passion for Zhuang language maintenance and authenticity among a driven few (Grey, 2017, Ch 7).

Because Standard Zhuang has not found many uses in commercial practices and commercial discourses - even as a commodified, written icon - and because symbolically powerful, national and global discourses normatively associate Putonghua and English with commerce, Zhuang is normatively out of place in commerce. The long-standing, historicallydeveloped association between Zhuang, poverty and incivility was never going to be upended by standardization alone and certainly has not been since nation policies and investments have refocused on Putonghua as the key linguistic instrument of economic development. The Bourdieusian critical sociolinguistic perspective here has helped us see this context of 
socially-situated beliefs and inequalities which were challenges in the standardization of Zhuang or, more accurately, were challenges that the standardization of Zhuang did not sufficiently engage with or overcome.

I do not claim that Standard Zhuang was designed to fail. When the reforms to Standard Zhuang took place in the early 1980s, the visual similarity between Romanized Zhuang and then-still-unfamiliar English may have been overlooked. Now, the entrenched visibility of English in China, particularly in globalized and marketized discourses, is something that language policy cannot eradicate. The visual similarity of Romanized Zhuang and Romanized Putonghua, and its effect on the recognizability of Standard Zhuang, also seems also to have been overlooked.

This chapter has shown that giving certain language practices hard edges, by which I mean giving a language variety official, standardized, symbolically powerful rules and forms, does not by itself create social value or valour or status for that language and its speakers. In fact, in this case study, standardization has not even produced more widespread or more standardized Zhuang language practices, let alone achieving those more ideological social impacts. This is a cautionary tale for those believing that standardization per se, without further effort and state backing, will future-proof a minority language. Standard Zhuang is an alternative technology that failed to take off both because the government did not support it and because market logics aggravated its obsolescence. Thus, it never acquired the cultural, economic or other capital that the initial standardizing policies may have anticipated; top-down standardization alone did not sufficiently imbue Zhuang language with symbolic power, or overcome the then-existing and continuing language ideologies that devalue Zhuang. Moreover, future-proofing Zhuang was not necessarily the goal of China's language standardizers. Standardizing Zhuang signalled that the government respected Zhuang speakers and treated their language equally with other official minority languages: That kind of state investment repays in political capital.

\section{References}

Ager, S. (2016) Zhuang (Vabcueyb/Vahcuengh). Omniglot: The online encyclopedia of writing systems and languages. See http://www.omniglot.com/writing/zhuang.htm (accessed July 2021).

Bourdieu, P. (1977) The economics of linguistic exchanges. Social Science Information $16(1), 645-688$.

Bourdieu, P. (1991) Language and Symbolic Power (J.B. Thompson, ed). Cambridge: Polity Press.

Brandist, C. (2005) Marxism and the philosophy of language in Russia in the 1920s and 1930s. Historical Materialism 13 (1), 63-84.

Chen, H. and Wang, L. (2005) 广西少数民族母语使用现状及趋势分析 [Status quo and development trend of the use of ethnic mother tongue in Guangxi]. In H. Chen and L. Li (eds) 广西语言文字使用问题调查与研究 [Investigation and Research on the Subject of Guangxi Languages and Scripts' Usage] (pp. 49-55). Nanning: Guangxi Education Press. 
Freeland, J. and Patrick, D. (2004) Language rights and language survival: Sociolinguistic and sociocultural perspectives. In J. Freeland and D. Patrick (eds) Language Rights and Language Survival (pp. 1-33). Manchester: St Jerome Publishing.

Grey, A. (2017) How do language rights affect minority languages in China? An ethnographic investigation of the Zhuang minority language under conditions of rapid social change. PhD thesis, Macquarie University. See http://www.languageonthemove. com/wp-content/uploads/2018/05/Grey_Zhuang_language_rights.pdf (accessed July 2021).

Grey, A. (2019a) A polity study of minority language management in China focusing on Zhuang. Current Issues in Language Planning 20 (5), 443-502. doi.org/10.1080/146 64208.2018.1502513

Grey, A. (2019b) Tourist tongues: High-speed rail carries linguistic and cultural urbanisation beyond the city limits in Guangxi, China. Applied Linguistics Review 12 (1), 11-37. doi.org/10.1515/applirev-2019-0099. Open Access

Grey, A. (2021a) Perceptions of invisible Zhuang minority language in Linguistic Landscapes of the People's Republic of China and implications for language policy. Linguistic Landscape https://doi.org/10.1075/11.20012.gre

Grey, A. (2021b) Language Rights in a Changing China: A National Overview and Zhuang Case Study. Boston: De Gruyter.

Guangxi Language Reform Committee (1989) 武鸣壮语语法 [A grammar of the Zhuang Dialect of Wuming]. Nanning: Minzu Press.

Guo, R., Bulag, U, Crang, M., Heberer, T., Hwang, E.-G., Milward, J., ... Guo, L.C. (eds) (2015) Multicultural China: A Statistical Yearbook (2014). Heidelberg: Springer.

GZAR Minority Language Working Group Research Team. (1984) Sawloib Cuengh Gun 壮汉词汇 [Zhuang Han Dictionary]. Nanning: 广西民族出版社 [Guangxi Nationalities Publishing House].

Heller, M. (2010) Language as a resource in the globalized new economy. In N. Coupland (ed.) Handbook of Language and Globalization (pp. 349-365). Oxford: Wiley-Blackwell.

Holm, D. (2008) The old Zhuang script. In A. Diller, J. Edmondson and Y. Luo (eds) The Tai-Kadai Languages (pp. 415-428). London: Routledge.

Holm, D. (2013) Mapping the Old Zhuang Character Script: A Vernacular Writing System from Southern China. Leiden: Brill.

Irvine, J. and Gal, S. (2000) Language ideology and linguistic differentiation. In P. Kroskrity (ed.) Regimes of Language: Ideologies, Polities, and Identities (pp. 35-83). Santa Fe: School of American Research Press.

Kaup, K. (2000) Creating the Zhuang: Ethnic Politics in China. Boulder: Lynne Rienner Publishers.

Landry, R. and Bourhis, R. (1997) Linguistic landscape and ethnolinguistic vitality: An empirical study. Journal of Language and Social Psychology 16 (1), 23-49. doi: 10.1177/0261927X970161002

Li, X. and Huang, Q. (2004) The introduction and development of the Zhuang writing system. In M. Zhou and H. Sun (eds) Language Policy in the People's Republic of China: Theory and Practice Since 1949 (pp. 239-256). Boston: Kluwer Academic Publishers.

Lu, H. and Li, F. (2012) Contact-induced change in status planing: A case study of Zhuang Putonghua. International Journal of the Sociology of Language 2012 (215 (May)), 19-40. doi:10.1515/ijsl-2012-0027

Luo, Y. (2008a) Sino-Tai and Tai-Kadai: Another look. In A. Diller, J. Edmondson and Y. Luo (eds) The Tai-Kadai Languages (pp. 9-28). London: Routledge.

Luo, Y. (2008b) Zhuang. In A. Diller, J. Edmondson and Y. Luo (eds) The Tai-Kadai Languages (pp. 317-377). London: Routledge.

Mullaney, T. (2006) Coming to terms with the nation: Ethnic classification and scientific statecraft in modern China, 1928-1954. PhD thesis, Columbia University. See http:// search.proquest.com/docview/305345129/ (accessed July 2021). 
Piller, I. (2015) Language ideologies. In K. Tracy (ed.) The International Encyclopedia of Language and Social Interaction (pp. 1-10). Boston : John Wiley \& Sons Inc.

Premaratne, D. (2015) Globalisation, language planning and language rights: The recent script policy measures adopted by Japan and the People's Republic of China. Current Issues in Language Planning 16 (4), 425-440. doi:10.1080/14664208.2014.979677

Ramsey, S. (1987) The Languages of China. Princeton: Princeton University Press.

Rohsenow, J. (2004) Fifty years of scrip and written language reform in the PRC. In M. Zhou and H. Sun (eds) Language Policy in the People's Republic of China: Theory and Practice since 1949 (pp. 21-44). Boston: Kluwer Academic Publishers.

Shohamy, E. (2006) Language Policy: Hidden Agendas and New Approaches. London: Routledge.

Sinj, B. and Loz, L. (2008) 900 Gawq Vahcuengh 壮语900句 900 Zhuang Language Phrases]. Nanning: Guangxi Nationalities Publishing House.

'Standard Zhuang'. (2018) See https://en.wikipedia.org/wiki/Standard_Zhuang (accessed July 2021).

Tapp, N. and Cohn, D. (2003) The Tribal Peoples of South West China. Bangkok: White Lotus.

Wang, J. (1979) 壮语 及壮汉人民怎样互学语言 [Zhuang Language How Zhuang and Han Peoples can Study Each Other's Language]. Beijing: 北京民族出版社[Beijing Nationalities Press].

Wang, J. (1983) 壮侗语族语言简志 [Zhuang and Dong Language Groups Language Simplified Aspiration]. Beijing: 北京民族出版社 [Beijing Nationalities Press].

Woolard, K. and Schieffelin, B. (1994) Language ideology. Annual Review of Anthropology 23, 55-82.

Yang, H. (2012) Naxi, Chinese and English: multilingualism in Lijiang. PhD thesis, Macquarie University. See: http://www.languageonthemove.com/wp-content/ uploads/2013/03/PhD_Thesis_Hongyan_Yang.pdf (accessed July 2021).

Zhou, M. (2000) Language policy and illiteracy in ethnic minority communities in China. Journal of Multilingual and Multicultural Development 21 (2), 129-148.

Zhou, M. (2001) Language policy and reforms of writing systems for minority languages in China. Written Language \& Literacy 4 (1), 31-65.

Zhou, M. (2003) Multilingualism in China: The Politics of Writing Reforms for Minority Languages, 1949-2002. Berlin: De Gruyter.

Zhou, M. (2012) Introduction: The contact between Putonghua (modern standard Chinese) and minority languages in China. International Journal of the Sociology of Language 2012 (215 (May)), 1-17. doi: 10.1515/ijsl-2012-0026

“独家]南宁路牌两种拼音 上为壮语下为汉语 (图) [(Exclusive) Nanning Street signs two kinds of Pinyin Zhuangyu above Hanyu below (picture)]'. (2009, 28/7/2009). online. Sina 新闻中心 [Sina News Centre]. See http://news.sina.com.cn/o/20090728/ 214716027776s.shtml (accessed July 2021). 